\title{
RUGOSIDADE SUPERFICIAL DO SOLO FORMADA POR ESCARIFICAÇÃO E INFLUENCIADA PELA EROSIVIDADE DA CHUVA ${ }^{(1)}$
}

\author{
Wilson Antonio Zoldan Junior ${ }^{(2)}$, Ildegardis Bertol ${ }^{(3)}$, Rafael \\ Pegoraro $^{(4)}$, Evandro Luiz Fabian ${ }^{(4)}$, Eduardo Zavaschi ${ }^{(4)} \&$ \\ Eva Vidal Vázquez ${ }^{(5)}$
}

\begin{abstract}
RESUMO
A rugosidade superficial do solo é influenciada, entre outros fatores, pelo efeito residual de manejo do solo, pelo tipo de preparo e pela erosividade da chuva e, juntamente com a cobertura do solo por resíduos vegetais, influencia a erosão hídrica. O objetivo deste trabalho foi determinar, entre junho de 2005 e março de 2006, em um Nitossolo Háplico alumínico típico, o efeito de uma operação de escarificador e da erosividade de chuvas sobre a rugosidade superficial, nos seguintes sistemas de manejo do solo: preparo convencional sem cultivo do solo (SCE), preparo convencional com cultivo do solo (PCE), semeadura direta em solo nunca preparado e com resíduos queimados (SQE) e semeadura direta tradicional (STE). Nos tratamentos PCE, SQE e STE, cultivaram-se aveia-preta, soja, ervilhaca comum, milho, aveia-preta, feijão preto, nabo forrageiro, soja, ervilhaca comum, milho e aveia-preta. Aplicaram-se cinco testes de chuva simulada, com $64 \mathrm{~mm} \mathrm{~h}^{-1}$ e duração de 20, 30, 40, 50 e 60 min cada um. Entre o segundo e o terceiro teste de chuva simulada ocorreram $57 \mathrm{~mm}$ de chuva natural; entre o terceiro e o quarto, $21 \mathrm{~mm}$; e entre o quarto e o quinto, $30 \mathrm{~mm}$. Determinou-se a rugosidade superficial imediatamente antes e logo após o preparo do solo com escarificador e imediatamente após cada teste de chuva simulada. A rugosidade original e linear da superfície do solo não foi influenciada pelo manejo, enquanto a rugosidade ao acaso teve essa influência, ao final de um pousio de seis meses. Diferentes sistemas de manejo do solo mantidos em pousio por seis meses resultaram em diferente
\end{abstract}

\footnotetext{
${ }^{(1)}$ Parte da Tese de Mestrado do primeiro autor. Recebido para publicação em dezembro de 2006 e aprovado em setembro de 2007.

(2) Mestrando do Departamento de Solos, Centro de Ciências Agroveterinárias, Universidade do Estado de Santa Catarina - CAV/ UDESC. Bolsista do PROMOP. E-mail: a6wazj@cav.udesc.br

(3) Professor do Departamento de Solos do Centro de Ciências Agroveterinárias, Universidade do Estado de Santa Catarina CAV/UDESC. CEP 88520-000, Lages (SC). E-mail: a2ib@cav.udesc.br

${ }^{(4)}$ Aluno do Curso de Agronomia, CAV/UDESC. Bolsista de Iniciação Científica do CNPq. E-mail: a8rp@cav.udesc.br

${ }^{(5)}$ Pesquisadora da Universidade de Santiago de Compostela, UCS, no Programa Juan de la Cierva, Ministério de Educación y Ciência. Espanha. E-mail: evavidal@mail2.udc.es
} 
rugosidade original, linear e ao acaso, quando o solo foi submetido à operação de escarificador. A rugosidade ao acaso foi menos influenciada pela declividade do terreno do que pelas marcas de preparo do solo, tendo diminuído com o aumento da erosividade das chuvas. Essa mesma rugosidade apresentou coeficiente de decaimento temporal semelhante nos sistemas de manejo do solo semeadura direta e preparo convencional.

Termos de indexação: microrrelevo superficial, decaimento da rugosidade, chuva simulada.

\title{
SUMMARY: SOIL SURFACE ROUGHNESS FORMED BY CHISELING AND AFFECTED BY RAINFALL EROSIVITY
}

\begin{abstract}
Surface soil roughness is affected by many factors, such as the residual effect of the soil management, tillage and rainfall erosivity and, together with the soil cover of crop residues, influences water erosion. The objective of this study was to determine the effects of a chiseling operation, together with rainfall erosivity, on soil surface roughness, from June 2005 to March 2006, in an aluminic Typical Hapludox, under the following soil management systems: bare soil under conventional tillage (BCT), cultivated soil under conventional tillage (CCT), no-tillage in a never-tilled soil with burnt plant residues (BNT), and traditional no-tillage (TNT). The crop sequence in the treatments CCT, BNT and TNT was black oat, soybean, common vetch, corn, black oat, common bean, fodder radish, soybean, common vetch, corn and black oat. Five simulated rain tests were applied, with a constant intensity of $64 \mathrm{~mm} \mathrm{~h}^{-1}$ and durations of 20,30,40,50, and $60 \mathrm{~min}$ each. Natural rains during the experimental period accounted for $57 \mathrm{~mm}$, between the $2^{\text {nd }}$ and $3^{\text {rd }}$ rainfall test; $21 \mathrm{~mm}$, between the $3^{\text {rd }}$ and $4^{\text {th }}$ test; and, $30 \mathrm{~mm}$, between the $4^{\text {th }}$ and $5^{\text {th }}$ test. The surface roughness was determined immediately before and immediately after the chiseling tillage, and immediately after each test of rain simulation. The original and linear soil surface roughness was not influenced by the management, unlike random roughness, at the end of a six-month fallow period. The original, linear and random roughness in different soil management systems was affected by a six-month fallow period, when the soil was subjected to chiseling. Random roughness was less influenced by soil slope than by tillage marks, which decreased with the increasing rainfall erosivity. The coefficient of decay of this kind of soil roughness was similar in the studied soil management systems under no tillage and conventional tillage.
\end{abstract}

Index terms: simulated rain, soil roughness decay, surface microrelief.

\section{INTRODUÇÃO}

A rugosidade ou microrrelevo superficial do solo refere-se ao enrugamento da superfície, caracterizado pela seqüência de microelevações e microdepressões espacialmente distribuídas (Allmaras et al., 1966). A rugosidade ao acaso refere-se às microelevações e microdepressões distribuídas ao acaso na superfície do solo; portanto, essa forma de rugosidade não contém a influência da declividade do terreno e das marcas de preparo do solo, sendo representada por um índice. Assim, o índice de rugosidade ao acaso descreve o intervalo vertical das microelevações e microdepressões, mas sem levar em conta a distribuição espacial dos pontos altos e baixos no espaço do microrrelevo (Linden \& van Doren Jr., 1986). A rugosidade da superfície do solo pode ainda conter a influência da declividade do terreno e das marcas de preparo do solo, denominada de rugosidade original, bem como apenas a influência das marcas de preparo do solo, denominada de rugosidade linear (Vidal Vázquez, 2002).

Geralmente, a rugosidade superficial é ocasionada por algum tipo de preparo mecânico do solo (Eltz \& Norton, 1997; Bertol et al., 2006; Castro et al., 2006), sendo, portanto, dependente do tipo e intensidade de preparo e do teor de água do solo antecedente ao preparo, da quantidade, tipo e manejo de resíduo vegetal no solo e do tipo de solo (Römkens \& Wang, 1986; Kamphorst et al., 2000; Bertol et al., 2006; Castro et al., 2006). Assim, a rugosidade é influenciada pelo sistema de manejo, pois este está relacionado, entre outros aspectos, ao preparo mecânico do solo. Desse modo, é de se esperar que o efeito 
residual do uso e manejo do solo tenha também efeito sobre a rugosidade, quando esta é produzida por algum tipo de preparo mecânico sobre o solo previamente manejado (Renard et al., 1997). Em um solo degradado fisicamente, por exemplo, a rugosidade ocasionada pelo preparo tende a ser menor do que no mesmo solo com estrutura de boa qualidade. Além disso, a persistência temporal da rugosidade superficial produzida sobre um solo preservado fisicamente é maior do que a mesma rugosidade produzida sobre um solo com estrutura degradada (Schick et al., 2000).

A diminuição da rugosidade ao longo do tempo é influenciada pela erosividade das chuvas, a qual é dependente do volume e intensidade destas e da enxurrada associada a tal chuva, bem como pelo tipo e manejo do solo e pelo grau de degradação de suas propriedades físicas (Cogo et al., 1984; Paz González \& Castro, 1996; Eltz \& Norton, 1997; Bertol et al., 2006; Castro et al., 2006). A chuva diminui a rugosidade, pois, ao incidir diretamente sobre o solo, a energia cinética das suas gotas provoca separação das partículas de solo na crista das microelevações, as quais são depositadas na base das microdepressões do microrrelevo. Assim, as ondulações do microrrelevo tendem a se tornar menos acentuadas ao longo da duração das chuvas.

O objetivo deste trabalho foi quantificar a rugosidade ocasionada por uma operação de escarificador efetuada sobre distintos sistemas de manejo do solo cultivados durante cinco anos e meio, bem como relacionar tal rugosidade com a erosividade das chuvas simuladas.

\section{MATERIAL E MÉTODOS}

O trabalho foi desenvolvido entre junho de 2005 e março de 2006, no Centro Educacional Profissionalizante Caetano Costa (CEDUP), em São José do Cerrito, SC, situado entre as coordenadas $28^{\circ} 56^{\prime}$ latitude sul e $51^{\circ} 09^{\prime}$ 'longitude, a oeste de Greenwich. O clima na região é do tipo $\mathrm{Cfb}$ (subtropical úmido), segundo a classificação de Köppen, e a altitude média do local é de $846 \mathrm{~m}$. O solo no local do experimento é um Nitossolo Háplico alumínico típico, o qual apresenta $23,3 \mathrm{~g} \mathrm{~kg}^{-1}$ de areia grossa, 44,1 $\mathrm{g} \mathrm{kg}^{-1}$ de areia fina, $615,0 \mathrm{~g} \mathrm{~kg}^{-1}$ de silte, $317,6 \mathrm{~g} \mathrm{~kg}^{-1}$ de argila total, $94,0 \mathrm{~g} \mathrm{~kg}^{-1}$ de argila dispersa em água, densidade de partículas de $2,80 \mathrm{~g} \mathrm{~cm}^{-3}$ e $32,0 \mathrm{~g} \mathrm{~kg}^{-1}$ de C orgânico, na média da camada de $0-0,2 \mathrm{~m}$. No quadro 1 são apresentados valores de densidade do solo, diâmetro médio ponderado de agregados e volume de macroporos na camada de 0,5 a 3,0 cm do solo, determinados antes do preparo do solo com escarificador e após o final dos testes de chuva simulada, em cada um dos tratamentos estudados.

A unidade experimental, ou parcela, tinha dimensões de $3,5 \mathrm{~m}$ de largura por $11,0 \mathrm{~m}$ de comprimento paralelo ao declive. Cada parcela era limitada na extremidade superior e nas laterais por chapas galvanizadas com 0,2 m de altura e cravadas $0,1 \mathrm{~m}$ no solo. A extremidade inferior era delimitada por uma calha coletora da enxurrada, que, conectada a um tubo de PVC, conduzia a enxurrada até o local de coleta, situado $6 \mathrm{~m}$ abaixo desta. Foram utilizadas oito parcelas, compreendendo quatro tratamentos com duas repetições, com amplitude de variação da declividade de 0,13 a $0,21 \mathrm{~m} \mathrm{~m}^{-1}$ entre parcelas (declividade média de $0,17 \mathrm{~m} \mathrm{~m}^{-1}$ ).

A pesquisa foi realizada em campo, sob condições de chuva simulada, com utilização de um aparelho simulador de chuvas de braços rotativos, o qual cobria simultaneamente duas parcelas experimentais, distanciadas de 3,5 m entre si (Embrapa, 1975), com intensidade de chuva planejada de $64 \mathrm{~mm} \mathrm{~h}^{-1}$. A erosividade das chuvas simuladas foi calculada seguindo o procedimento descrito em Meyer (1958).

Os tratamentos de manejo do solo estudados foram: (1) preparo convencional sem cultivo do solo

Quadro 1. Densidade do solo (Ds), diâmetro médio ponderado de agregados (DMP) e macroporosidade (Ma), determinados antes da operação de escrificação e após os testes de chuva simulada, em diferentes sistemas de manejo de um Nitossolo Háplico (média de duas repetições)

\begin{tabular}{|c|c|c|c|c|c|c|}
\hline \multirow{2}{*}{ Tratamento } & \multicolumn{3}{|c|}{ Antes da escarificação } & \multicolumn{3}{|c|}{ Após os testes de chuva } \\
\hline & Ds & DMP & Ma & Ds & DMP & Ma \\
\hline & $\mathrm{kg} \mathrm{dm}^{-3}$ & $\mathrm{~mm}$ & $\mathrm{dm}^{3} \mathrm{dm}^{-3}$ & $\mathrm{~kg} \mathrm{dm^{-3 }}$ & $\mathrm{mm}$ & $\mathrm{dm}^{3} \mathrm{dm}^{-3}$ \\
\hline $\mathrm{SCE}$ & $0,86 \mathrm{c}$ & $1,90 \mathrm{c}$ & $0,27 \mathrm{a}$ & $0,98 \mathrm{a}$ & $1,63 \mathrm{c}$ & $0,22 \mathrm{c}$ \\
\hline $\mathrm{PCE}$ & $0,96 \mathrm{~b}$ & $5,34 \mathrm{a}$ & $0,27 \mathrm{a}$ & $1,01 \mathrm{a}$ & $3,14 \mathrm{~b}$ & $0,22 \mathrm{c}$ \\
\hline SQE & $0,97 \mathrm{~b}$ & $5,29 \mathrm{a}$ & $0,24 \mathrm{a}$ & $0,85 \mathrm{~b}$ & $4,68 \mathrm{a}$ & $0,27 \mathrm{~b}$ \\
\hline STE & $1,06 \mathrm{a}$ & $4,76 \mathrm{~b}$ & $0,17 \mathrm{~b}$ & $0,86 \mathrm{~b}$ & $4,10 \mathrm{a}$ & $0,34 \mathrm{a}$ \\
\hline
\end{tabular}

SCE: solo sem cultivo; PCE: preparo convencional; SQE: semeadura direta queimada; STE: semeadura direta tradicional. Médias seguidas da mesma letra na coluna não diferem pelo teste de Duncan a $5 \%$. 
durante cinco anos e meio. Fez-se uma aração a $0,20 \mathrm{~m}$ e duas gradagens a $0,15 \mathrm{~m}$ de profundidade no sentido paralelo ao declive duas vezes ao ano e efetuaram-se escarificações manuais. O solo permaneceu sem preparo e efetuaram-se capinas e escarificações manuais nos últimos seis meses. A superfície do solo foi mantida livre de vegetação e desprovida de crosta superficial durante cinco anos e meio - no final deste período, fez-se uma escarificação mecânica (SCE); (2) preparo convencional com cultivo do solo durante cinco anos e meio. Fez-se uma aração a $0,20 \mathrm{~m}$ e duas gradagens a $0,15 \mathrm{~m}$ de profundidade duas vezes ao ano. Os resíduos culturais foram incorporados ao solo durante cinco anos, e o de aveia, mantido na superfície do solo durante os últimos seis meses - no final deste período, foi retirado, fazendo-se uma escarificação mecânica (PCE); (3) semeadura direta em campo natural cultivado sem preparo do solo durante cinco anos e meio. Os resíduos vegetais do campo (antes do primeiro cultivo) e das culturas (após os demais cultivos) foram queimados. Assim, no final do período de cinco anos e meio, queimou-se o resíduo cultural de aveia e fez-se uma escarificação mecânica (SQE); e (4) semeadura direta a partir do segundo cultivo do solo, implantada sobre preparo convencional efetuado no momento da instalação da área experimental (primeiro cultivo - há cinco anos e meio), denominada semeadura direta tradicional. Os resíduos culturais foram mantidos na superfície do solo. Ao final do período de cinco anos e meio, retirouse o resíduo cultural de aveia da superfície do solo e fez-se uma escarificação mecânica (STE). Nos tratamentos PCE, SQE e STE, cultivaram-se aveiapreta (Avena strigosa), soja (Glycine max), ervilhaca comum (Vicia sativa), milho (Zea mays), aveia-preta, feijão preto (Phaseolus vulgaris), nabo forrageiro (Raphanus sativus), soja, ervilhaca comum, milho e aveia-preta. A retirada do resíduo de aveia dos tratamentos PCE e STE e a queima dele no SQE foi realizada em 11 de janeiro de 2006. A escarificação foi efetuada em 12 de janeiro de 2006, sobre o solo com teor de água aproximadamente no ponto de friabilidade. O escarificador, acionado por trator no sentido paralelo ao declive, possuía 13 hastes distanciadas $0,25 \mathrm{~m}$ uma das outras, que trabalharam a uma profundidade de $0,18 \mathrm{~m}$.

Nos tratamentos foram aplicados cinco testes de chuva simulada, a seguir descritos: primeira chuva, aplicada em 12/1/2006, com duração de 20 min, um dia após a realização de escarificação do solo; segunda chuva, com duração de 30 min, quatro dias após a primeira; terceira chuva, com duração de $40 \mathrm{~min}$, sete dias após a segunda; quarta chuva, com duração de 50 min, nove dias após a terceira; e quinta chuva, com duração de 60 min, seis dias após a quarta chuva.

A superfície do solo permaneceu descoberta durante o período experimental e, no intervalo de algumas chuvas simuladas, ocorreram chuvas naturais. Entre a segunda e a terceira chuva simulada, houve precipitação de $57 \mathrm{~mm}$ de chuva natural, tendo sido $50 \mathrm{~mm}$ no dia 18/1/2006 e $7 \mathrm{~mm}$ em 22/1/2006. Entre a terceira e a quarta chuva simulada, houve $21 \mathrm{~mm}$ de chuva natural, no dia 31/1/2006, e entre a quarta e a quinta, $30 \mathrm{~mm}$ de chuva natural, no dia 6/2/2006.

A rugosidade superficial do solo foi avaliada imediatamente antes e após o preparo do solo com escarificador e imediatamente após os testes de chuva simulada. Para efetuar as leituras do microrrelevo superficial, utilizou-se um rugosímetro com 20 varetas de $\mathrm{Al}$, com $600 \mathrm{~mm}$ de comprimento e $8 \mathrm{~mm}$ de diâmetro cada uma, distanciadas $30 \mathrm{~mm}$ uma das outras e distribuídas ao longo de uma linha no suporte do rugosímetro, ao qual estava acoplada uma câmara fotográfica digital distanciada $1,80 \mathrm{~m}$ do conjunto de varetas. Isso possibilitou a tomada de uma fotografia do conjunto de varetas que refletiam as alturas da superfície do solo, localizadas transversalmente ao declive da parcela experimental. Movendo-se o conjunto de varetas sobre o suporte do rugosímetro, em 20 posições na direção da pendente da parcela, em distâncias de $30 \mathrm{~mm}$ uma das outras, tomaram-se 20 fotografias em cada parcela. A digitalização das fotografias permitiu a leitura de 400 pontos de altura da superfície do solo em cada parcela, em uma área de amostragem de $0,36 \mathrm{~m}^{2}(0,6 \times 0,6 \mathrm{~m})$.

$\mathrm{O}$ índice de rugosidade foi calculado como sendo o desvio-padrão das alturas, utilizando os dados de altura da superfície do terreno sem transformação e sem eliminar os seus valores extremos, pelo método proposto por Kamphorst et al. (2000). O índice foi obtido com os dados em três condições: mantendo no cálculo os efeitos da declividade do terreno e das marcas do preparo do solo (rugosidade original); mantendo no cálculo o efeito das marcas do preparo e retirando o efeito da declividade (rugosidade linear); e retirando do cálculo simultaneamente os efeitos da declividade e das marcas do preparo (rugosidade ao acaso, RR).

A significância estatística dos efeitos dos tratamentos sobre as variáveis estudadas, quando pertinente, foi testada por meio de análise da variância, segundo o delineamento inteiramente casualizado, em quatro duplas de tratamentos, sendo cada dupla composta por duas repetições. As diferenças entre médias foram comparadas pelo teste de Duncan a $5 \%$. Os dados de rugosidade linear foram relacionados aos respectivos dados originais, e os dados de rugosidade ao acaso, aos respectivos dados lineares, utilizando modelo linear do tipo $y=a+b x$. Foram feitas relações entre os índices de rugosidade ao acaso e a erosividade das chuvas, utilizando modelo exponencial do tipo $\mathrm{y}=\mathrm{ae}^{-\mathrm{bx}}$. Este modelo é recomendado para relacionar o decaimento da rugosidade superficial do solo em função da erosividade da chuva, pois a rugosidade decresce mais rapidamente no início da ocorrência de chuvas erosivas e menos rapidamente no seu final, conforme constatado por Cogo (1981), Eltz \& Norton (1997) e Vidal Vázquez (2002). 


\section{RESULTADOS E DISCUSSÃO}

\section{Rugosidade superficial original do solo}

Os valores do índice de rugosidade original do solo, antes do preparo com escarificador, variaram de 21,6 a 33,6 mm (Quadro 2). Esses valores foram relativamente altos, comparados aos encontrados por Bertol et al. (2006), que variaram de 8,2 a 16,2 $\mathrm{mm}$. Isso é explicado pela elevada declividade do terreno e pela presença de marcas de preparo do solo e de sulcos de erosão. No trabalho desses autores, a declividade do terreno era menor e as marcas de preparo menos evidentes do que no deste estudo. Além disso, esses autores trabalharam sobre um Inceptissolo, diferente, portanto, do Nitossolo, o que certamente também influenciou a diferença de tais valores. Os valores da rugosidade original não diferiram entre tratamentos, devido, provavelmente, ao pousio do solo durante seis meses, tempo este suficiente para que a superfície do solo se tornasse igual nos diferentes tipos de preparo, em termos de microrrelevo.

A escarificação não ocasionou diferença na rugosidade original em relação à ausência do preparo, em todos os tratamentos (Quadro 2). Essa falta de diferença se deveu à declividade do terreno e às marcas de preparo do solo. Vidal Vázquez (2002) e Bertol et al. (2006) encontraram diferença comparando a rugosidade superficial antes e após o preparo do solo, possivelmente porque nesses trabalhos os autores utilizaram outros tipos de solo (Latossolo no caso de Vidal Vázquez e Inceptissolo no caso de Bertol et al.), nos quais esse tipo de preparo forma torrões de maior tamanho. Além disso, é provável que o solo estivesse mais seco no momento do preparo no caso dos trabalhos desses autores, o que também ocasionou torrões maiores. O maior valor de rugosidade original, após o preparo com escarificador, foi observado no SQE. Isso ocorreu pelo fato de que este tratamento mantinha as propriedades originais do solo (campo natural), pois este nunca fora preparado, embora tenha sofrido a queima continuada dos resíduos vegetais. No entanto, é interessante observar que este tratamento apresentava rugosidade mais elevada mesmo antes do preparo com escarificador. Assim, no SQE, a escarificação promoveu aumento de $22 \%$ na rugosidade, enquanto no $\mathrm{PCE}$, por exemplo, tal aumento foi de $47 \%$.

As chuvas simuladas aplicadas não influenciaram a rugosidade original do solo (Quadro 2). Isso indica que o período de tempo em que o solo permaneceu em pousio (seis meses) foi suficiente para proporcionar consolidação e, assim, diminuir o efeito residual do manejo anterior do solo sobre a rugosidade, quando este foi submetido à operação de escarificação. Além disso, a declividade do terreno e as marcas de preparo e de erosão do solo continuaram exercendo forte influência na rugosidade original, quando o solo foi submetido às chuvas, a ponto de mascarar o efeito destas na redução da rugosidade. Portanto, esses dados são discordantes daqueles obtidos por Vidal Vázquez (2002) e Bertol et al. (2006), pois estes autores trabalharam sobre solos diferentes do utilizado no presente estudo (Latossolo e Inceptissolo).

\section{Rugosidade superficial linear do solo}

Os valores do índice de rugosidade linear do solo variaram de 7,5 a $10,9 \mathrm{~mm}$, antes do preparo (Quadro 3). Comparados aos valores obtidos por Vidal Vázquez (2002), que variaram de 7,2 a 51,0 mm, eles foram relativamente baixos. Explica-se: no trabalho desse autor, a declividade do terreno era menor e as marcas de preparo do solo eram expressivamente

Quadro 2. Rugosidade original do solo ocasionada por uma operação de escarificador sobre diferentes sistemas de manejo, antes e após escarificação e após aplicação de chuvas simuladas, em um Nitossolo Háplico (média de duas repetições)

\begin{tabular}{|c|c|c|c|c|}
\hline Tratamento & SCE & PCE & SQE & STE \\
\hline $\mathrm{ANP}$ & $27,8 \mathrm{Aa}$ & $21,6 \mathrm{Aa}$ & $33,6 \mathrm{Aa}$ & $26,2 \mathrm{Aa}$ \\
\hline $\mathrm{APP}$ & $36,1 \mathrm{Ba}$ & $31,7 \mathrm{Ca}$ & $41,1 \mathrm{Aa}$ & $36,9 \mathrm{Ba}$ \\
\hline $\mathrm{AT} 1$ & $36,8 \mathrm{Aba}$ & $30,0 \mathrm{Ba}$ & $45,9 \mathrm{Aa}$ & $39,3 \mathrm{~A} \mathrm{Ba}$ \\
\hline $\mathrm{AT} 2$ & $29,8 \mathrm{Aa}$ & $29,4 \mathrm{Aa}$ & $42,8 \mathrm{Aa}$ & $36,3 \mathrm{Aa}$ \\
\hline AT3 & $28,5 \mathrm{Aa}$ & $27,6 \mathrm{Aa}$ & $39,4 \mathrm{Aa}$ & $34,4 \mathrm{Aa}$ \\
\hline $\mathrm{AT} 4$ & $28,7 \mathrm{ABa}$ & $25,0 \mathrm{Ba}$ & $41,3 \mathrm{Aa}$ & $31,3 \mathrm{ABa}$ \\
\hline AT5 & $27,9 \mathrm{Ba}$ & $26,1 \mathrm{Ba}$ & $45,9 \mathrm{Aa}$ & $29,0 \mathrm{Ba}$ \\
\hline
\end{tabular}

SCE: solo sem cultivo; PCE: preparo convencional; SQE: semeadura direta queimada; STE: semeadura direta tradicional; ANP: antes da escarificação; APP: após escarificação; AT1, AT2, AT3, AT4 e AT5: após os testes 1, 2, 3, 4 e 5 de chuva simulada, respectivamente. Médias seguidas da mesma letra, maiúscula na linha e minúscula na coluna, não diferem pelo teste de Duncan a $5 \%$. CV: $15,8 \%$ 
Quadro 3. Rugosidade linear do solo ocasionada por uma operação de escarificador sobre diferentes sistemas de manejo, antes e após escarificação e após aplicação de chuvas simuladas, em um Nitossolo Háplico (média de duas repetições)

\begin{tabular}{|c|c|c|c|c|}
\hline Tratamento & SCE & PCE & SQE & STE \\
\hline $\mathrm{ANP}$ & $7,5 \mathrm{Cb}$ & $10,9 \mathrm{Ac}$ & $9,2 \mathrm{Be}$ & $8,2 \mathrm{Bcd}$ \\
\hline $\mathrm{APP}$ & $16,4 \mathrm{Ba}$ & $22,6 \mathrm{ABa}$ & $27,1 \mathrm{Aa}$ & $25,3 \mathrm{Aa}$ \\
\hline $\mathrm{AT} 1$ & $16,7 \mathrm{Ba}$ & $20,3 \mathrm{ABab}$ & $21,7 \mathrm{Abb}$ & 23,2 Acab \\
\hline $\mathrm{AT} 2$ & $15,1 \mathrm{Aa}$ & 18,9 Acab & $20,2 \mathrm{Abc}$ & $24,5 \mathrm{Aab}$ \\
\hline AT3 & $13,4 \mathrm{Aab}$ & 17,1 Acab & 17,7 Adc & $16,2 \mathrm{Acadb}$ \\
\hline $\mathrm{AT} 4$ & $14,5 \mathrm{Aab}$ & 13,9 Acab & $15,5 \mathrm{Ad}$ & 14,9 Acdb \\
\hline AT5 & $19,3 \mathrm{Aa}$ & $13,0 \mathrm{Acb}$ & $14,7 \mathrm{Ad}$ & 13,9 Acd \\
\hline
\end{tabular}

SCE: solo sem cultivo; PCE: preparo convencional; SQE: semeadura direta queimada; STE: semeadura direta tradicional; ANP: antes da escarificação; APP: após escarificação; AT1, AT2, AT3, AT4 e AT5: após os testes 1, 2, 3, 4 e 5 de chuva simulada, respectivamente. Médias seguidas da mesma letra, maiúscula na linha e minúscula na coluna, não diferem pelo teste de Duncan a $5 \%$. CV: $18,7 \%$.

menores do que as observadas no presente trabalho. Assim, naquele trabalho, a declividade do terreno e as marcas de preparo do solo apresentavam contribuição relativamente menor para o índice de rugosidade linear do que neste. Os valores da rugosidade linear antes da operação de preparo com escarificador diferiram entre tratamentos (com exceção do SQE e STE), devido ao efeito de consolidação do solo, que se refletiu na rugosidade após a escarificação, e, principalmente, à retirada do efeito da declividade do terreno no procedimento de cálculo desse tipo de rugosidade. Nesse caso, o $\mathrm{SQE}$ foi o tratamento mais eficaz em aumentar a rugosidade ao ser submetido à escarificação.

A operação de preparo do solo com escarificador aumentou a rugosidade linear em relação à observada antes do preparo, em todos os tratamentos (Quadro 3), conforme também constatado por Vidal Vázquez (2002) e Bertol et al. (2006). A diferença, nesse caso, se deveu à retirada do efeito da declividade do terreno para o cálculo, mantendo-se apenas o efeito das marcas de preparo do solo e de erosão hídrica preexistentes. A maior rugosidade linear foi ocasionada pela escarificação sobre os dois tratamentos de semeadura direta, STE e SQE, pelo fato de que, neles, as propriedades do solo foram mantidas mais próximas das originais (campo natural). No STE, o preparo do solo foi efetuado há cinco anos e meio e, na SQE, o solo nunca fora preparado, embora os resíduos vegetais tivessem sido queimados continuadamente.

As chuvas simuladas aplicadas, em geral, influenciaram a rugosidade linear do solo. Houve tendência de diminuição dos valores com o aumento da erosividade das chuvas, com exceção do SCE (Quadro 3). Esse fato indica que a declividade do terreno e as marcas de preparo do solo não exerceram influência nesse tipo de rugosidade, quando o solo foi submetido às chuvas, conforme constatado também por Vidal Vázquez (2002) e Bertol et al. (2006).

\section{Rugosidade superficial ao acaso do solo}

Os valores do índice de rugosidade ao acaso, antes do preparo com escarificador, variaram de 4,2 a 7,7 mm (Quadro 4). Comparados aos obtidos por Vidal Vázquez (2002), que variaram de 3,8 a 38,6 mm, por Bertol et al. (2006), de 5,4 a 12,1 mm, e por Castro et al. (2006), de 10,5 a $12,0 \mathrm{~mm}$, esses valores foram relativamente baixos. Isso se deve ao fato de que nos trabalhos desses autores a declividade do terreno e as marcas de preparo do solo eram menores do que as do presente trabalho. Assim, naqueles trabalhos, essas variáveis apresentavam contribuição relativamente menor para o índice de rugosidade ao acaso do que neste. Os valores da rugosidade ao acaso diferiram entre tratamentos, pelo fato de que, neles, o solo consolidou-se de maneira diferente, o que se refletiu diferenciadamente na rugosidade provocada pelo escarificador. No entanto, o principal fator que contribuiu para isso foi a retirada do efeito da declividade do terreno e das marcas de preparo do solo no procedimento de cálculo, conforme constatado também por Cogo et al. (1984), Eltz \& Norton (1997), Vidal Vázquez (2002), Bertol et al. (2006) e Castro et al. (2006). Assim, retirando-se o efeito dessas duas variáveis da rugosidade, o microrrelevo superficial do solo foi representado apenas pela distribuição espacial e casual das microelevações e microdepressões.

A operação de preparo do solo com escarificador aumentou a rugosidade ao acaso em relação à observada antes do preparo, em todos os tratamentos (Quadro 4), conforme constatado também por Cogo et al. (1984), Eltz \& Norton (1997), Vidal Vázquez (2002), 
Quadro 4. Rugosidade ao acaso do solo ocasionada por uma operação de escarificador sobre diferentes sistemas de manejo, antes e após escarificação e após aplicação de chuvas simuladas, em um Nitossolo Háplico (média de duas repetições)

\begin{tabular}{|c|c|c|c|c|}
\hline Tratamento & SCE & PCE & SQE & STE \\
\hline ANP & 4,2 $\mathrm{Bb}$ & $7,7 \mathrm{Ac}$ & $4,9 \mathrm{Bd}$ & $5,6 \mathrm{ABd}$ \\
\hline $\mathrm{APP}$ & $9,9 \mathrm{Ba}$ & $16,8 \mathrm{Aa}$ & $18,0 \mathrm{Aa}$ & $20,6 \mathrm{Aa}$ \\
\hline $\mathrm{AT} 1$ & $8,2 \mathrm{Bab}$ & $14,4 \mathrm{Aab}$ & $15,1 \mathrm{Ab}$ & $17,6 \mathrm{Aab}$ \\
\hline AT2 & 7,6 Bab & 12,0 Acab & $13,9 \mathrm{Ab}$ & $12,9 \mathrm{Acb}$ \\
\hline AT3 & $5,1 \mathrm{Bb}$ & $9,6 \mathrm{ABcb}$ & $10,6 \mathrm{Abc}$ & $11,9 \mathrm{Ac}$ \\
\hline $\mathrm{AT} 4$ & $5,6 \mathrm{Aab}$ & $9,4 \mathrm{Acb}$ & $9,5 \mathrm{Ac}$ & $11,2 \mathrm{Ac}$ \\
\hline AT5 & $9,6 \mathrm{Aa}$ & $8,5 \mathrm{Ac}$ & $8,7 \mathrm{Ac}$ & 9,4 Acd \\
\hline
\end{tabular}

SCE: solo sem cultivo; PCE: preparo convencional; SQE: semeadura direta queimada; STE: semeadura direta tradicional; ANP: antes da escarificação; APP: após escarificação; AT1, AT2, AT3, AT4 e AT5: após os testes 1, 2, 3, 4 e 5 de chuva simulada, respectivamente. Médias seguidas da mesma letra, maiúscula na linha e minúscula na coluna, não diferem pelo teste de Duncan a $5 \%$. CV: $18,7 \%$.

Bertol et al. (2006) e Castro et al. (2006). Essa diferença deve-se à retirada do efeito da declividade do terreno e das marcas de preparo do solo e erosão hídrica preexistentes, para o cálculo. A maior rugosidade ao acaso foi ocasionada pela escarificação sobre os dois tratamentos de semeadura direta, STE e SQE, e sobre o PCE. No caso do STE e SQE, isso se deveu ao fato de que estes tratamentos mantiveram as propriedades do solo mais próximas das originais (campo natural), embora no STE o solo tenha sido preparado há cinco anos e meio. No caso do SQE, as boas propriedades físicas do solo foram mantidas, embora se tenha efetuado a queima continuada dos resíduos vegetais. Em se tratando do PCE, o período de tempo de seis meses que o solo permaneceu em pousio desde a última operação de preparo foi suficiente para consolidar a superfície e, com isso, ocasionar rugosidade ao acaso em valor igual ao dos tratamentos STE e SQE, por ocasião da operação de escarificação.

As chuvas simuladas influenciaram a rugosidade ao acaso do solo, com forte tendência de diminuição dos valores devido ao aumento da erosividade, com exceção do SCE (Quadro 4). Isso ocorreu devido às gotas de chuva, que desgastaram as microelevações da superfície do solo. Os sedimentos, separados da massa do solo, depositaram-se nas microdepressões, conforme constatado por Cogo et al. (1984), Eltz \& Norton (1997), Vidal Vázquez (2002), Bertol et al. (2006) e Castro et al. (2006). Esse comportamento indica, ainda, que a declividade do terreno e as marcas de preparo do solo não exerceram influência alguma nesse tipo de rugosidade quando o solo foi submetido às chuvas, especialmente nos tratamentos PCE, SQE e $\mathrm{STE}$, os quais apresentaram valores de rugosidade superficial ao acaso iguais entre si, tanto imediatamente após o preparo do solo com escarificador quanto após o final dos testes de chuva simulada aplicada. Isso revela que o efeito do manejo anterior do solo, diferente nos tratamentos durante cinco anos e meio, não se refletiu na rugosidade ao acaso ocasionada pelo escarificador (imediatamente após o preparo) nem na resistência de tal rugosidade diante da ação das chuvas simuladas aplicadas. A razão disso foi o período de tempo de seis meses em que tais tratamentos permaneceram em pousio, entre o último cultivo e a aplicação da operação de escarificador para início deste trabalho.

\section{Relação entre rugosidade linear e original, entre rugosidade ao acaso e linear e entre rugosidade ao acaso e erosividade da chuva}

O baixo valor do coeficiente de determinação indica que a rugosidade linear dependeu fracamente da rugosidade original do solo (Figura 1). Isso mostra que a declividade do terreno teve influência relativamente baixa sobre a rugosidade superficial produzida pela operação de escarificação. O coeficiente angular da reta indica que, para $1 \mathrm{~mm}$ de aumento da rugosidade original, a rugosidade linear aumentou em $0,40 \mathrm{~mm}$. Portanto, a retirada do efeito da declividade do terreno dos dados originais de elevação da superfície do solo, quando do cálculo da rugosidade linear, pouco influenciou os valores dessa variável, conforme constatado também por Vidal Vázquez (2002).

O alto coeficiente de determinação da equação da reta que relacionou a rugosidade ao acaso com a rugosidade linear indica elevado grau de dependência dessas duas formas de rugosidade (Figura 2). Assim, a rugosidade superficial do solo foi menos alterada pela retirada do efeito da declividade do terreno dos dados 


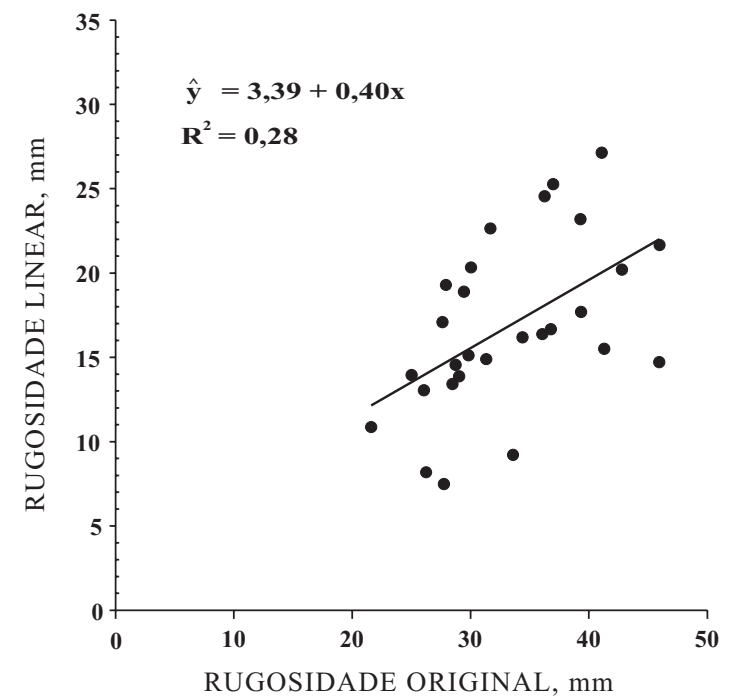

Figura 1. Relação entre a rugosidade original e a rugosidade linear da superfície de um Nitossolo Háplico, sob diversos sistemas de manejo do solo submetidos a uma operação de escarificador (média de duas repetições).

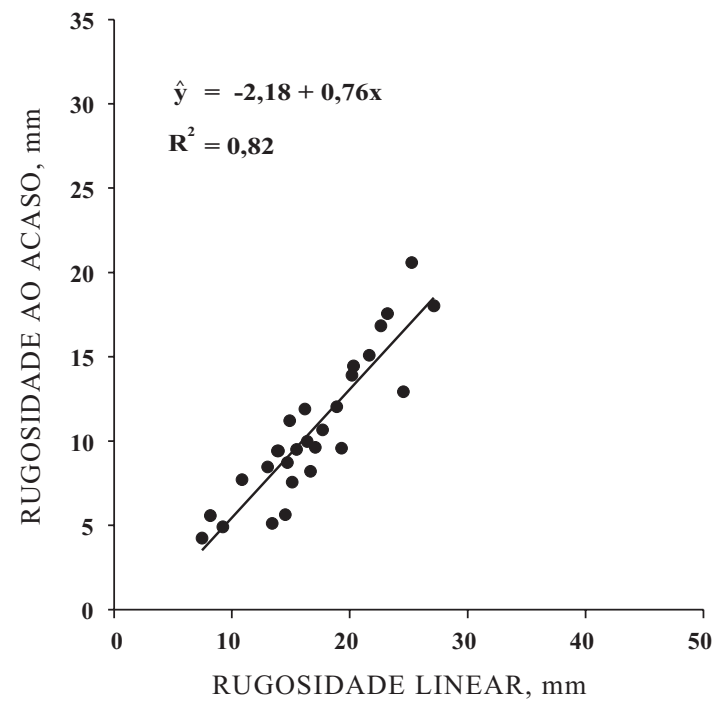

Figura 2. Relação entre a rugosidade linear e a rugosidade ao acaso da superfície de um Nitossolo Háplico, sob diversos sistemas de manejo do solo submetidos a uma operação de escarificador (média de duas repetições).

originais de elevação da superfície do solo, para cálculo da rugosidade linear (Figura 1), do que pela retirada conjunta do efeito da declividade do terreno e das marcas de preparo do solo dos referidos dados originais, para cálculo da rugosidade ao acaso (Figura 2). Portanto, a rugosidade superficial do solo foi mais fortemente influenciada pelas marcas de preparo do solo do que pela declividade do terreno, o que está em concordância com Vidal Vázquez (2002) e Bertol et al. (2006).
A aplicação de $61 \mathrm{~mm}$ de chuva simulada (referente à primeira e segunda chuvas), com erosividade total equivalente a $911 \mathrm{MJ} \mathrm{mm} \mathrm{ha}^{-1} \mathrm{~h}^{-1}$, na média dos tratamentos, ocasionou expressiva diminuição na rugosidade ao acaso, em comparação com a rugosidade ao acaso imediatamente após o preparo com escarificador (Figura 3). A aplicação de $181 \mathrm{~mm}$ de chuva simulada (referente à terceira, quarta e quinta chuvas), mais a precipitação de $108 \mathrm{~mm}$ de chuvas naturais, com erosividade total equivalente a $3.138 \mathrm{MJ} \mathrm{mm} \mathrm{ha}^{-1} \mathrm{~h}^{-1}$, na média dos tratamentos, por outro lado, ocasionou pequena redução da rugosidade em comparação àquela após aplicação dos $61 \mathrm{~mm}$ iniciais de chuvas. Esse comportamento confirma que a rugosidade ao acaso da superfície do solo é mais fortemente diminuída pelo efeito das chuvas iniciais do que pelo das chuvas finais, conforme constatado também por Cogo (1981), Cogo et al. (1984), Eltz \& Norton (1997) e Bertol et al. (2006).

Os coeficientes de decaimento da rugosidade ao acaso da superfície do solo, em decorrência das chuvas simuladas aplicadas, foram baixos, em especial no SCE (Figura 3), comparados aos valores obtidos por Cogo et al. (1984), Eltz \& Norton (1997) e Vidal Vázquez (2002), provavelmente devido ao fato de que cada um desses autores trabalhou sobre solo distinto em relação aos outros, tanto em termos de tipo de solo quanto em termos de grau de degradação física. Neste trabalho, o estudo foi desenvolvido em Nitossolo, portanto, expressivamente mais argiloso e com teor de óxido de Fe e $\mathrm{Al}$ e de matéria orgânica maior do que o dos solos utilizados pelos demais autores. Os tratamentos PCE, SQE e STE apresentaram os maiores valores de decaimento da rugosidade devido à elevada consolidação do solo, que se refletiu em elevado valor de DMP dos agregados (Quadro 1). Essa consolidação estava presente, no caso do SQE, pelo fato de o solo nunca ter sido mobilizado mecanicamente, o que contribuiu para que fossem mantidas as condições físicas muito próximas das originais do campo natural, apesar da queima dos resíduos vegetais. No STE, a consolidação do solo ocorreu durante os cinco anos e meio em que o solo deste tratamento foi manejado em forma de semeadura direta; no PCE, tal consolidação ocorreu no período de tempo de seis meses em que o tratamento foi mantido em pousio após o último preparo efetuado em experimento anterior. Assim, percebe-se que esses três tratamentos, apesar de terem sido manejados de maneira distinta desde a implantação da área experimental (cinco anos e meio antes deste trabalho), praticamente não variaram quanto ao decaimento da rugosidade ao acaso ao terem sido submetidos à operação com escarificador. No SCE, o baixo decaimento da rugosidade ao acaso é explicado pelo já baixo valor dessa rugosidade existente imediatamente após o preparo do solo com escarificador e imediatamente antes da aplicação dos testes de chuva simulada, mas, principalmente, pelo fato de a superfície do solo ter sido sulcada pela ação da enxurrada nos últimos testes de chuva simulada. 


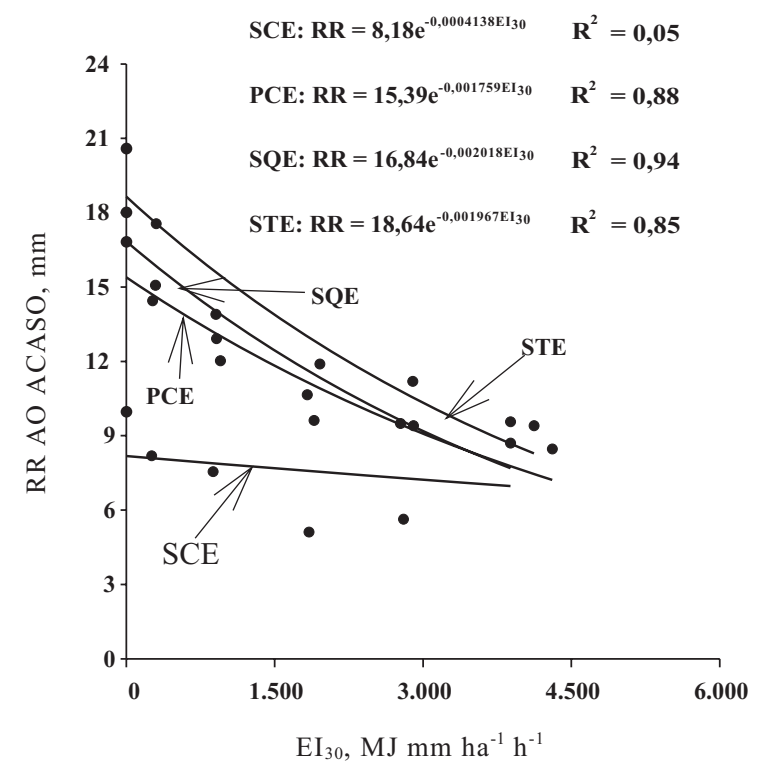

Figura 3. Relação entre a rugosidade ao acaso (RR) da superfície de um Nitossolo Háplico e o índice de erosividade das chuvas, $\mathrm{EI}_{30}$, sob diversos sistemas de manejo do solo submetidos a uma operação de escarificador (média de duas repetições). SCE: solo sem cultivo; PCE: preparo convencional; SQE: semeadura direta queimada; STE: semeadura direta tradicional.

Esses sulcos de erosão foram parcialmente computados no cálculo da rugosidade, aumentando-a, em especial na avaliação final.

\section{CONCLUSÕES}

1. A rugosidade original e linear da superfície do solo não foi influenciada pelo manejo, enquanto a rugosidade ao acaso sofreu tal influência, no final de um pousio de seis meses.

2. Diferentes sistemas de manejo do solo mantidos em pousio por seis meses resultaram em diferentes rugosidades original, linear e ao acaso, quando o solo foi submetido à operação de escarificador.

3. A rugosidade ao acaso da superfície do solo foi menos influenciada pela declividade do terreno do que pelas marcas de preparo do solo produzidas por uma operação de escarificador.

4. A rugosidade ao acaso da superfície do solo produzida por uma operação de escarificador diminuiu com o aumento da erosividade das chuvas.

5. A rugosidade ao acaso produzida por uma operação de escarificador sobre os sistemas de manejo do solo semeadura direta e preparo convencional apresentou semelhante coeficiente de decaimento temporal.

\section{AGRADECIMENTOS}

Ao Conselho Nacional de Desenvolvimento Científico e Tecnológico - CNPq, pela bolsa de pesquisa $\mathrm{PQ}$ e pelos recursos financeiros (Edital Universal 019/ 2004); à UDESC, pela bolsa (PROMOP); e ao Ministério da Educação e Ciência da Espanha, por parte dos recursos financeiros (projeto CGL2005-08219-C02-01).

\section{LITERATURA CITADA}

ALLMARAS, R.R.; BURWELL, R.E.; LARSON, W.E. \& HOLT, R.F. Total porosity and random roughness of the interrow zone as influenced by tillage. USA, Conserv. Res. Rep., 7:1-14, 1966.

BERTOL, I.; AMARAL, A.J.; VIDAL VÁZQUEZ, E.; PAZ GONZÁlEZ, A. \& BARBOSA, F.T. Relações da rugosidade superficial do solo com o volume de chuva e com a estabilidade de agregados em água. R. Bras. Ci. Solo, 30:543-553, 2006.

CASTRO, L.G.; COGO, N.P. \& VOLK, L.B.S. Alterações na rugosidade superficial do solo pelo preparo e pela chuva e sua relação com a erosão hídrica. R. Bras. Ci. Solo, 30:339352,2006 .

COGO, N.P. Effect of residue cover, tillage-induced roughness and slope lenght on erosion and related parameters. West Lafayette, Purdue University, 1981. 344p. (Tese de Doutorado)

COGO, N.P.; MOLDENHAUER, W.C. \& FOSTER, G.R. Soil loss reductions from conservation tillage practices. Soil Sci. Soc. Am. J., 48:368-373, 1984.

ELTZ, F.L.F. \& NORTON, L.D. Surface roughness changes as affected by rainfall erosivity, tillage and canopy cover. Soil Sci. Soc. Am. J., 61:1.746-1.755, 1997.

EMPRESA BRASILEIRA DE PESQUISA AGROPECUÁRIA EMBRAPA. Recomendações gerais do encontro sobre uso do simulador de chuva em pesquisa de conservação do solo no Brasil. In: ENCONTRO NACIONAL SOBRE PESQUISA DE EROSÃO COM SIMULADORES DE CHUVA, 1975, Londrina. Resumos. Londrina, Empresa Brasileira de Pesquisa Agropecuária, 1975. p.107-120.

KAMPHORST, E.C.; JETTEN, V.; GUÉRIF, J.; PITKÄNEN, J.; IVERSEN, B.V.; DOUGLAS, J.T. \& PAZ, A. Predicting depressional storage from soil surface roughness. Soil Sci. Soc. Am. J., 64:1749-1758, 2000.

LINDEN, D.R. \& van DOREN JR., D.M. Parameters for characterizing tillage-induced soil surface roughness. Soil Sci. Soc. Am. J., 50:1560-1565, 1986.

MEYER, L.D. An investigation of methods for simulating rainfall on standard runoff plots and a study of the drop size, velocity, and kinetic energy of selected spray nozzles. West Lafayette, USDA - ARS - SWCRD - ESWMRB and Purdue University, 1958. 43p. 1958. (Special Report, 81)

PAZ GONZÁlez, A. \& CASTRO, M.T.T. Medida del microrrelieve del suelo y estimación de la retención hídrica en depresiones de la superficie. In: GRANDAL D’ANGLADE, A. \& PAGÉS VALCARLOS, J.L., eds. REUNIÓN DE GEOMORFOLOGIA, 4., La Coruña, 1996. p.829-841. 
RENARD, K.G.; FOSTER, G.R.; WEESIES, G.A.; McCOOL, D.K. \& YODER, D.C. Predicting soil erosion by water: A guide to conservation planning with the revised universal soil loss equation (RUSLE). Washington, U.S. Department of Agriculture, 1997. 384p. (Agriculture Handbook, 703)

RÖMKENS, M.J.M. \& WANG, J.Y. Effect of tillage on soil roughness. Am. Soc. Agric. Eng., 29:429-433, 1986.
SCHICK, J.; BERTOL, I.; BATISTELA, O. \& BALBINOT JÚNIOR, A.A. Erosão hídrica em Cambissolo Húmico alumínico submetido a diferentes sistemas de preparo e cultivo do solo: I. Perdas de solo e água. R. Bras. Ci. Solo, 24:427-436, 2000.

VIDAL VÁZQUEZ, E. Influencia de la precipitación y el laboreo en la rugosidad del suelo y la retención de agua en microdepresiones. La Coruña, Universidade de Coruña, 2002. 430p. (Tese de Doutorado) 